\title{
Sürtünme Karıştırma Kaynağı ile Birleştirilmiş AA7075 ve AZ31B Alaşımlarının Kaynak Kalitesi Üzerine Çalışma
}

\author{
${ }^{* 1}$ Musa BİLGIN, ${ }^{1}$ Şener KARABULUT, ${ }^{2}$ Ahmet ÖZDEMİR \\ ${ }^{1}$ Department of Mechanical Program, Hacettepe University, Turkey \\ ${ }^{2}$ Faculty of Technology, Department of Manufacturing Engineering, Gazi University, Turkey
}

\begin{abstract}
Özet
Bu çalışmada AZ31B magnezyum ve AA7075 alüminyum plakalar sürtünme karıştırma kaynağ 1 yöntemi ile birleştirilmiş ve numunelerin kaynak kalitesi tahribatlı ve tahribatsız muayene yöntemleri kullanılarak incelenmiş̧tir. Kaynatılmış numuneleri kıyaslamak için AA7075-AA7075, AZ31B-AZ31B ve AA7075-AZ31B plakalar, 500 dev/dak takım dönme hızı, $20 \mathrm{~mm} /$ dak takım ilerleme hızı ve $0,8 \mathrm{~mm}$ ilerleme tarafına takım ofseti ile $1^{\circ}$ 'lik takım açısı birleștirilmișlerdir. Hızlı soğuma sonucu oluşan termal çatlakları önlemek için kaynak hattına sıcak hava uygulaması yapılmıştır. Birleştirilen numunelerin kaynak kalitesi sıvı penetrant, radyografik inceleme ve çekme testi deneyleri ile araştırılmıştır. Test sonuçları kaynak kökü üzerinde başarılı bir birleştirmenin elde edildiğini ancak karıştırma bölgesinde tünel oluşumunun meydana geldiğini göstermiştir. Aynı özellikteki Al-Al ve Mg-Mg plakalarının SKK yöntemi ile birleştirilmesinde kabul edilebilir bir çekme dayanımı değeri elde edilirken farklı özellikteki $\mathrm{Al}$ ve $\mathrm{Mg}$ alaşımlarının birleştirilmesinde ise daha düşük çekme dayanımı oluştuğu görülmüştür.
\end{abstract}

Anahtar Kelimeler: Sürtünme karıştırma kaynağı, $\mathrm{Al}$ alaşımı, Mg alaşımı, Tahribatsız muayene, Çekme testi

\section{Study on Welding Quality of AA7075 and AZ31B Alloys Combined with Friction Stir Welding}

\begin{abstract}
In this study, AZ31B magnesium and AA7075 aluminum sheets were joined by friction stir welding (FSW) method and joint quality of specimens was examined by using destructive and non-destructive methods. To compare the welded samples, AA7075-AA7075, AZ31B-AZ31B and AA7075-AZ31B sheets were combined with a tool rotation speed of $500 \mathrm{rpm}$, a tool feed rate of $20 \mathrm{~mm} / \mathrm{min}$ and a tool offset of $0.8^{\circ}$ on the advancing side with a tool tilt angle of $1^{\circ}$. The heated air was applied to the welded line in order to prevent thermal cracks caused by rapid cooling. The joint quality of the welded specimens was investigated by liquid penetrant, radiographic examination, and tensile strength test experiments. The test results showed that a successful joint was achieved on the weld root. However, the tunnel formation was observed at the bottom side of the weld root. An acceptable tensile strength value was obtained in joining $\mathrm{Al}-\mathrm{Al}$ and $\mathrm{Mg}-\mathrm{Mg}$ sheets due to the similar mechanical and microstructural properties of the specimens during the FSW process, while lower tensile strength was measured in dissimilar FSW of $\mathrm{Al}$ and $\mathrm{Mg}$ alloys.
\end{abstract}

Keywords: Friction stir welding, $\mathrm{Al}$ alloy, $\mathrm{Mg}$ alloy, non-destructive inspection, Tensile strength

*Corresponding author: Address: Department of Mechanical Program, Hacettepe University, 06935, TURKEY. e-mail address: musabilgin@ hacettepe.edu.tr, Phone: +903122673020 


\section{Giriş}

Havacılık, uzay, ulaşım ve askeri sanayinin odak noktası, araçları hafifleştirme ve manevra kabiliyetini artırmaktır. Fakat güvenlik, performans ve kullanım kolaylığı açısından artan müşteri talepleri; taşıtlardaki yapısal bileşenlerin ortalama ağırlığın artmasına neden olmaktadır. Bu nedenle taşıtların yapısal bileşenlerinin yoğunluğu düşük malzemeler ile elde edilmesi, güvenlikten ödün verilmeden yapılacak en önemli tasarım değişikliğidir. Hafiflik ve dayanım özelliklerini bir arada bulunduran alüminyum ve magnezyumun alaşımları ürünlerde hafifliğin sağlanması için çözüm noktasında bulunmaktadır.

Al alaşımlarının katılaşma esnasında yapısal dönüşüm eksiklileri, yüksek elektrik ve termal iletkenlikleri ergitme kaynağında sorun oluşturmaktadır [1]. Al alaşımlarının yüksek 1sıl genleşme ve katılaşma aralıklarının geniş olması nedeniyle ergitme kaynağında oluşan yüksek 1sı girdisi kaynak dikişinde çatlak oluşumuna neden olurken; aynı zamanda 1sının tesiri altındaki bölgede (ITAB)tane sınırlarında düşük ergime derecesine sahip fazların oluşumuna sebebiyet vererek tane sınırlarında katılaşma çatlamalarına yol açmaktır [2, 3]. Mg alaşımlarının ise yüksek reaktifesi ve yanıcılığından dolayı kaynak edilebilirliği oldukça karmaşıktır [4, 5]. Bu dezavantajların yanında $\mathrm{Al} / \mathrm{Mg}$ alaşımlarının ergitme kaynak yöntemleri ile birleştirilmesinde oluşan iri taneli, gevrek ve yüksek sertlikteki Al-Mg intermetalik bileşiklerin kötü mekanik özellikleri sebebiyle kaynak dayanımını düşürmektedir [6-8].

SKK yönteminde ana metal erimediğinden ergitme kaynağı yönteminde katılaşma ile ilgili ortaya çıkan problemler ortadan kalmaktadır [9]. Bu nedenle günümüzde $\mathrm{Al}$ ve $\mathrm{Mg}$ alaşımlarının birleştirilmesinde SKK yöntemi odak noktası haline gelmiştir. Araştırmacılar $\mathrm{Al}$ ve $\mathrm{Mg}$ alaşımlarının hem aynı alaşımlar hem de farklı alaşımlarının birleştirilmesi üzerine yoğun olarak çalışmaktadır [10 - 14].

Bu çalışmada, SKK işlemi sırasında kaynak hattına sıcak hava uygulaması yapılarak birleştirilen AA 7075-T6 ve AZ31B alaşımlarının kaynak kalitesi araştırılmıştır. Deneylerde Al-Al, Mg-Mg ve Al-Mg plakalar birleştirilmiş tahribatsız muayene yöntemleri ile analiz edilmiş ve birleştirilen numunelerin çekme dayanımları araştırılmıştır.

\section{Malzeme ve Metod}

SKK işlemleri TOS OLOMOUC FGU 32 üniversal freze tezgâhında yapılmıştır. Deneylerde AA7075-T6 ve AZ31B plakalar kullanılmıştır. Birleştirilen plakaların boyutları $300 \mathrm{~mm} \times 100 \mathrm{~mm}$ × 5 mm'dir. Al ve $\mathrm{Mg}$ alaşımlarının kimyasal bileşimleri Tablo 1'de mekanik özellikleri Tablo 2'de verilmiştir. Deneylerde $20 \mathrm{~mm}$ omuz çapı ve 4,80 mm pim uzunluğuna sahip K10 kalite karbür üçgen profilli karıştırıcı takım kullanılmıştır.

Tablo 1. AA7075 - T6 ve AZ31B alaşımlarının kimyasal bileşimi

\begin{tabular}{|c|c|c|c|c|c|c|c|c|c|c|c|c|}
\hline \multirow{2}{*}{ Malzeme } & \multicolumn{10}{|c|}{ Alassim Elementleri $(\%$ Ă̆ırlık } \\
\cline { 2 - 13 } & $\mathrm{Si}$ & $\mathrm{Fe}$ & $\mathrm{Cu}$ & $\mathrm{Mn}$ & $\mathrm{Ni}$ & $\mathrm{Zn}$ & $\mathrm{Ti}$ & $\mathrm{Cr}$ & $\mathrm{Ca}$ & $\mathrm{Al}$ & $\mathrm{Mg}$ & $\mathrm{Diğ}$. \\
\hline AA 7075-T6 & 0,07 & 0,12 & 1,39 & 0,059 & 0,0039 & 5,63 & 0,026 & 0,18 & --- & Kal. & 2,45 & --- \\
\hline AZ31B & 0,01 & 0,004 & $<0,0005$ & 0,29 & 0,0013 & 0,75 & --- & --- & $<0,005$ & 2,9 & Kal. & $<0,3$ \\
\hline
\end{tabular}


Tablo 2. AA7075 - T6 ve AZ31B alaşımlarının mekanik özellikleri

\begin{tabular}{|c|c|c|c|}
\hline Malzeme & Çekme dayanımı $(\mathrm{MPa})$ & Kopma Uzaması (\%) & Akma Dayanımı (MPa) \\
\hline AA7075-T6 & 580 & 13 & 510 \\
\hline AZ31B & 240 & 7 & 140 \\
\hline
\end{tabular}

SKK işleminin sırasında numunelerin sabitlenmesi için özel bir bağlama kalıbı tasarımı ve imalatı yapılmıştır. Kaynak işlemi sırasında oluşan ısının numuneler üzerinde homojen dağılımını sağlamak için bağlama kalıbının gövdesi AA7075-T6 malzeme kullanılarak yapılmıştır. Ayrıca kaynak bölgesinin de kontrollü soğuması sağlanarak birleştirilen numunelerin ani soğumalar ve devamında oluşan artık gerilmelerden dolayı çatlak oluşumunu engellenmesi hedeflenmiştir. Kontrollü soğutma işlemi için $480{ }^{\circ} \mathrm{C}$ sıcak hafa üfleme kapasitesine sahip lehim sökme işleminde kullanılan XYTRONIC marka LF 853D model sıcak hava üfleme cihazı kullanılmıştır (Şekil 1).

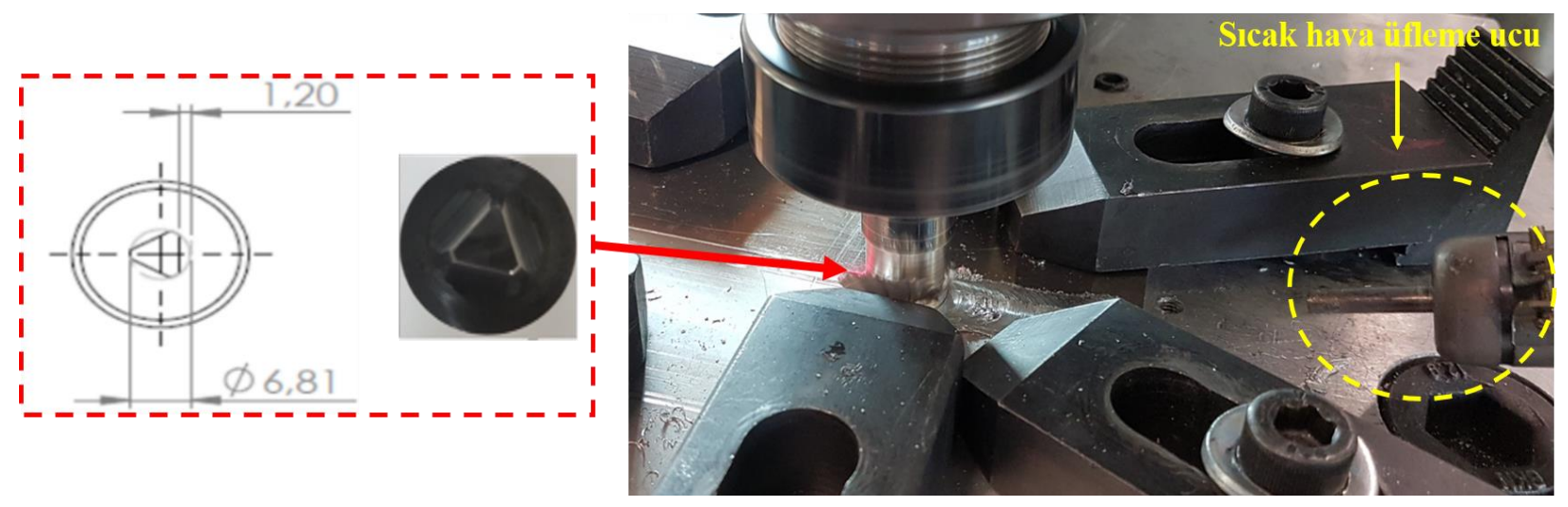

Şekil 1. Deney düzeneği ve karıştırıcı takım

SKK işlemleri Al-Al, Mg-Mg ve Al-Mg alaşımları olmak 3 farklı şekilde malzeme gruplandırılması yapılarak gerçekleştirilmiştir. Al-Mg alaşımlarının birleştirilmesin AZ31B Mg alaşımı ilerleme tarafına, AA 7075-T6 Al alaşımı geri çekme tarafına konumlanmıştır. SKK işlemlerinde takım dönme hız1 $500 \mathrm{dev} / \mathrm{dak}$, ilerleme hız1 $20 \mathrm{~mm} /$ dak, ilerleme tarafina $0.8 \mathrm{~mm}$ takım ofseti ve takım açısı $1^{\circ}$ seçilerek yapılmıştır. Karıştırıcı takımın dalma hızı 6 mm/dak'dır. Karıştırıcı takıma gerekli dalma derinliği verildikten sonra yeterli 1sı oluşumu için karıştırıcı takım 1 dak süre ile hareket etmeden bekletilmiştir.

Birleştirilen numunelerin yüzey kusurlarının daha net belirlenmesi için TS EN ISO 3452-1 [15], TS EN ISO 3452-2 [16], TS EN ISO 23277 [17] ve TS EN ISO 3059:2012 [18] standartlarına uygun olarak sıvı penetrant testi yapılmıştır. Sıvı penetrant testi için yüzeyi hazırlanan numunelerin ilk olarak BT 69 numaralı temizleme spreyi ile yüzey temizlenmiş ve daha sonra sırasıyla BT 68 numaralı sıvı penetrant, son olarak ta BT 70 geliştirici sprey uygulanmıştır.

Kaynak hattı bölgesindeki kaynak kusurlarının belirlenmesi için radyografik incelemeler yapılmıştır. Radyografik incelemeler YXLON marka MGC-41 model dijital radyografi muayene sistemi ile (Şekil 2) EN 17636-2 standardına uygun olarak gerçekleştirilmiştir. 

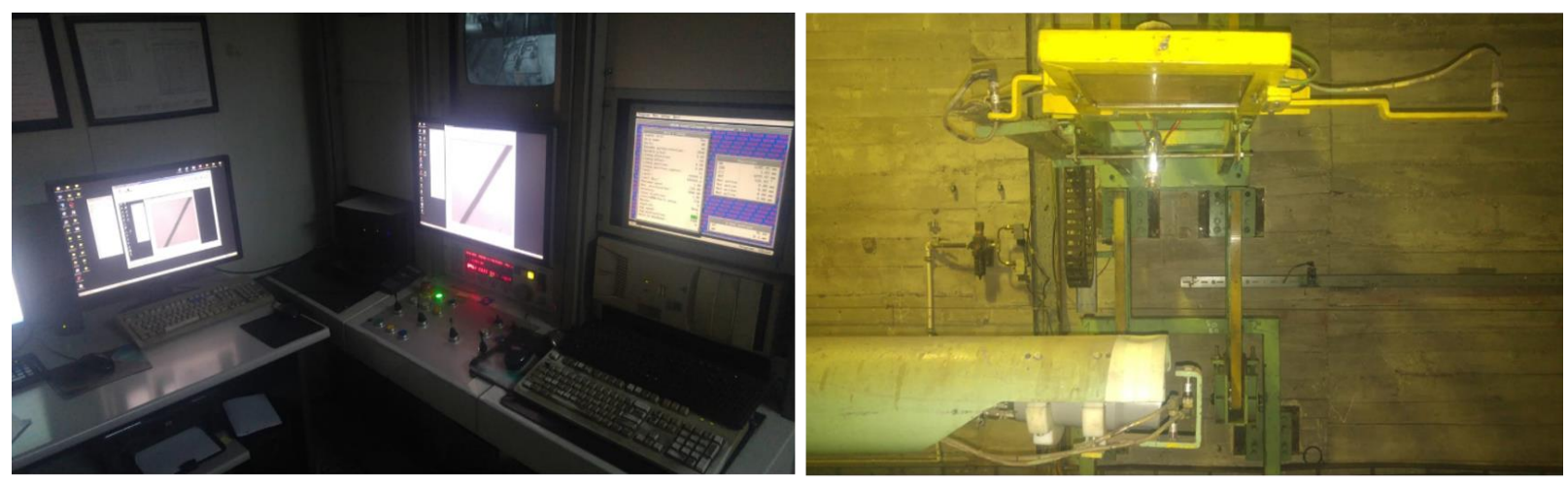

Şekil 2. Radyografik muayene sistemi

Çekme testi numuneleri Mitsubishi marka MV 1200S model tel erozyon tezgâhında hazırlanmıştır. Birleştirilen numunelerin her birinden çekme testinde kullanmak üzere üçer adet test numunesi hazırlanmıştır. Çekme sonuçlarının değerlendirilmesinde her üç testin aritmetik ortalaması alınmıştır.

Çekme numuneleri ASTM E8/E8M-09 [19] standardına göre hazırlanmıştır (Şekil 3). Çekme testleri $50 \mathrm{kN}$ kapasiteye sahip Instron 3369 çekme test cihazında $1 \mathrm{~mm} /$ dak çekme hızında gerçekleştirilmiştir.

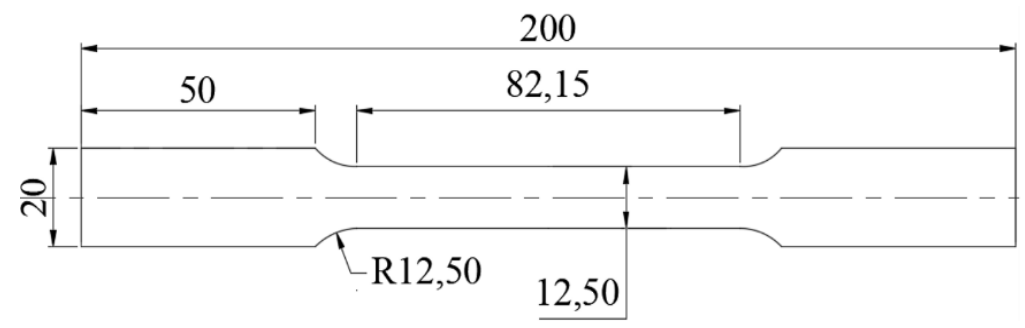

Şekil 3. Çekme numunesi ölçüleri

\section{Deneysel Sonuçlar ve Tartışma}

Deneyler sonucunda elde edilen numunelerin makro görünümleri Şekil 4'de verilmiştir. Numuneler gözle muayene edildiğinde $\mathrm{Al}-\mathrm{Mg}$ ve $\mathrm{Mg}-\mathrm{Mg}$ kaynağın başlangıç kısmında boşluklar olduğu ancak başarılı bir birleştirme elde edildiği görülmektedir. Boşluklarının işlem başlangıcında ve SKK işleminde $\mathrm{Al}$ alaşımlarına göre daha az ısı açığa çıkmasını sağlayan $\mathrm{Mg}$ alaşımının birleştirilmesinde oluşması düşük 1sı girdisi nedeniyle plastik deformasyonun zorlaşması sonucu meydana geldiği ön görülmektedir [10, 20]. Makro resimler incelendiğinde $\mathrm{Al}-\mathrm{Mg}$ ve $\mathrm{Mg}-\mathrm{Mg}$ malzemelerde oluşan boşluk kusurlarının genellikle ilerleme tarafında konumlandığı görülmüştür. Bu durumun, ilerleyen takımın meydana getirdiği boşluğu plastik deformasyona uğrayan malzemenin tam olarak dolduramamasının neden olduğu düşünülmektedir. Mg-Mg alaşımlarının birleştirilmesinde kaynak hattının orta kısmında boşluk oluşumu meydana gelmiştir. Oluşan boşluğun sürekli bir yapıya sahip olmaması, işlem esnasında sıcaklıkta meydana gelen ani dalgalanmanın bir sonucu olduğu düşünülmektedir. 
Şekil 4'de görüleceği üzere, Al-Al alaşımının birleştirilmesinde oldukça düzgün bir kaynak hattı elde edilmiş ve kaynak yüzeyinde herhangi bir kaynak kusuru gözlenmemiştir. Al-Al birleştirmesinde boşluk kusurunun oluşmaması homojen 1 sı dağılımından ve SKK işleminde Al alaşımlarının $\mathrm{Mg}$ alaşımlarına nazaran daha fazla 1Sı oluşturmasından kaynaklandığı değerlendirilmektedir.
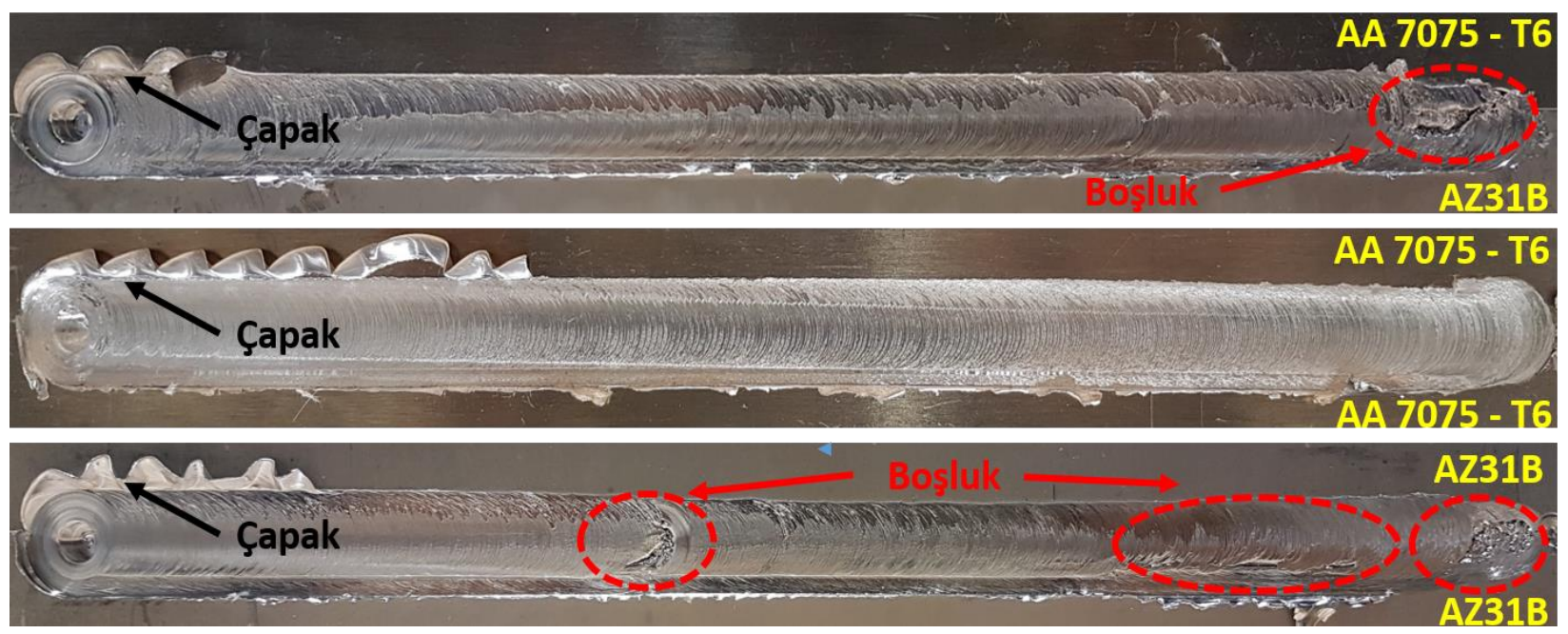

Şekil 4. SKK yöntemi ile birleştirilen Al-Mg, Al-Al, Mg-Mg malzeme çiftlerinin genel görünümü

SKK işleminde $\mathrm{Al}$ alaşımlarının Mg alaşımlarına göre daha fazla 1sı açığa çıkarmasının iki nedeni vardır; sürtünme ile $\mathrm{Al}$ alaşımları daha fazla 1sı üretmesi [21,22] ve malzemelerin farklı atomik yapıya sahip olmalarıdır [23, 24]. Al alaşımları yüzey merkezli kübik yapıya sahip olduklarından hegzagonal sıkı paket yapıya sahip Mg alaşımlarına göre daha fazla aktif kayma bandına sahiptirler. $\mathrm{Bu}$ durum $\mathrm{Al}$ alaşımlarının daha çok plastik deformasyona uğramasını sağlayarak açığa çıkan ısı miktarını artırtmaktadır [23, 24].

Her üç birleştirmede birleştirme hattı sonuna doğru çapak oluşumu gözlemlenmektedir. Çapak oluşumu SKK işleminde karıştırıcı takımın dalma derinliğinin ya da uygulanan eksenel kuvvetin fazla olması durumunda kaynak metalinin takım omzundan dişarı çıkması sonucunda meydana gelmektedir. Yapılan birleştirmelerde incelendiğinde çapak oluşumunun işlemin sonuna doğru gerçekleşmiş olması birleştirilen malzemelerin sünek yapısından kaynaklanmaktadır. İşlem esnasında yüksek basınç ve sıcaklık nedeniyle takım omzuna malzeme sıvanması olmaktadır bu durum bağımlı değişken olan eksenel kuvvetin değişimini sağlamaktadır. Al-Al birleştirmesinde çapak oluşumunun daha önce gerçekleşmesi; $\mathrm{Al}$ alaşımlarının SKK yöntemi ile birleştirilmesinde $\mathrm{Mg}$ alaşımlarına göre daha fazla ısı açığa çıkarması sonucu karıştıııı takıma malzeme yapışmasının daha önce gerçekleşerek dalma kuvvetinin artışına neden olmaktadır. Yüksek dalma kuvveti ise deforme olmuş malzemenin incelmesine ve bunun sonucu olarak malzemenin takımın omuz kısmından çıkarak çapak oluşmasına neden olur [23 - 26].

Al ve Mg alaşımlarının birleştirilmesinde, karıştırıcı takımın sürtünerek geçtiği kaynak hattının oda sıcaklığında 1sıl dengeye geçmesiyle, birleşme bölgesinin hızlı bir şekilde soğumaya başlamakta ve devamında sıcak çatlaklara neden olduğu bilinmektedir [10]. Bu nedenle yüzey kusurlarının daha 
net belirlenmesi için birleştirilen numunelere penetrant testi yapılmıştır (Şekil 5). Penetrant testi incelendiğinde gözle muayene işleminde belirlenen kusurlar dışında herhangi mikro kusur ya da çatlak oluşumu gözlemlenmemiştir. Al-Mg alaşımlarının birleştirilmesinde ani soğumaları ve devamında artık gerilmelerle birlikte çatlak oluşumu meydana gelmektedir. SKK sonrası çatlamanın önlenmesi için birleştirme bölgesine kaynak işlemi sonrası sıcak hava üflenerek gerçekleştirilen kontrollü soğutma işleminin başarıya ulaştı̆̆ı görülmüştür.

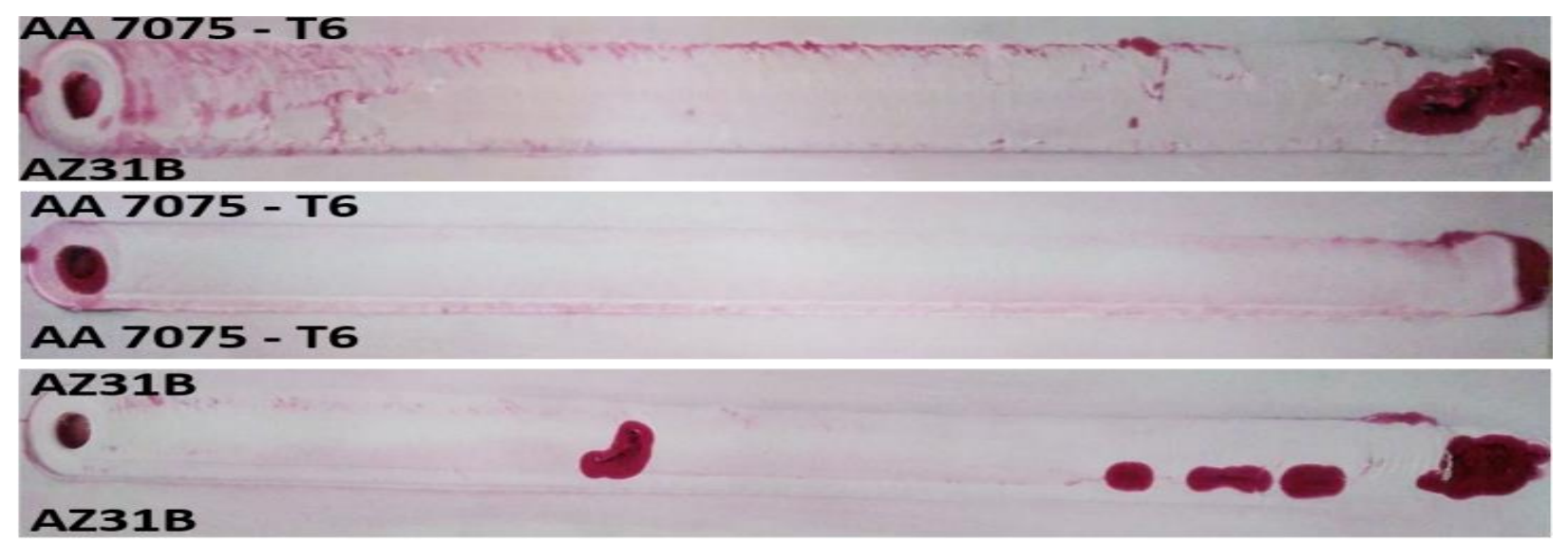

Şekil 5. Penetrant testi uygulanmış $\mathrm{Al}-\mathrm{Mg}, \mathrm{Al}-\mathrm{Al}, \mathrm{Mg}-\mathrm{Mg}$ malzeme çiftleri

Gözle yapılan muayenelerde başarılı bir birleştirme elde edildiği görülürken, radyografik muayene sonuçları her üç birleştirme türünde de tünel oluşumlarının meydana geldiğini göstermiştir (Şekil 6). Tünel oluşumunun işlem esnasında düşük 1sı girdisi nedeniyle malzemelerin yeterli plastik deformasyona uğramamasından dolayı meydana geldiği değerlendirilmektedir. Al-Al alaşımının birleştirilmesinde gözlemlenen tünel oluşumuna kaynak yüzeyinde elde edilen yeterli ve homojen 1sı dağılımın kaynak kökünde elde edilememesinin neden olduğu düşünülmektedir.

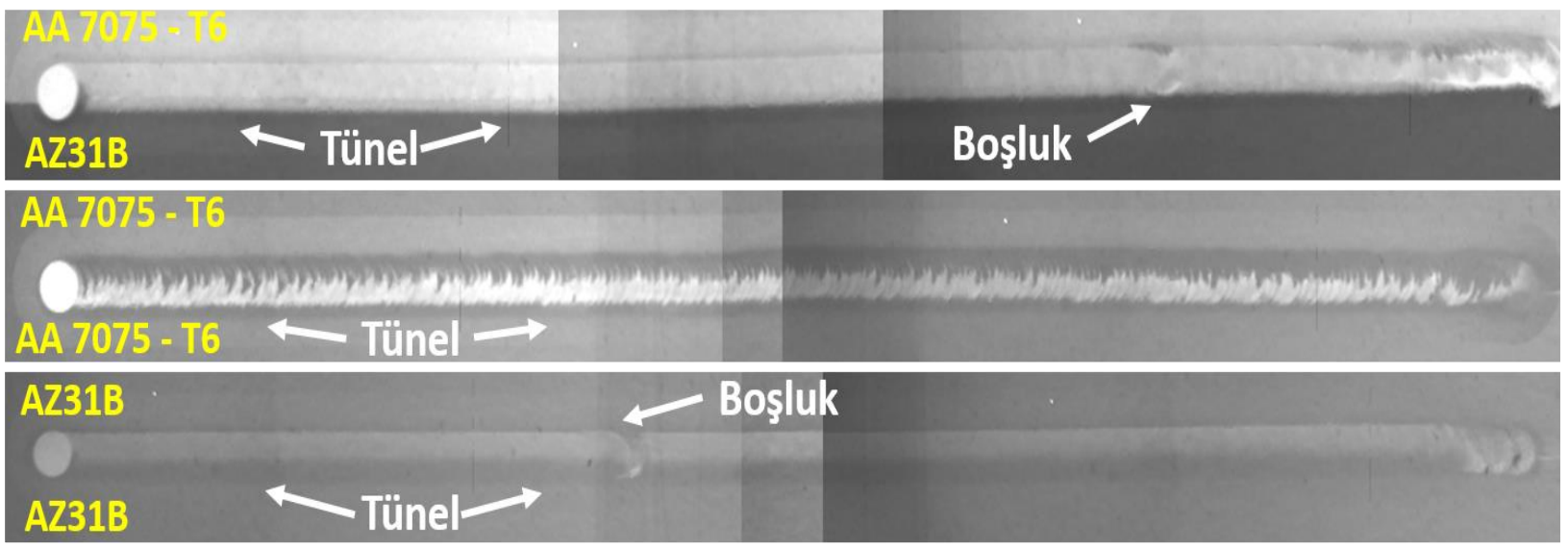

Şekil 6. Radyografik muayene uygulanmış Al-Mg, Al-Al, Mg-Mg malzeme çiftleri

Ayrıca ilerleme tarafında malzeme takıma ters akış göstermesi ve pimin açtığı boşluğu doldurmak için daha uzun akış mesafesi gerekmesinden dolayı 1sı girdisi daha yüksek olmaktadır [27]. Bu 
durum üstün mekanik özelliklere sahip AA 7075 - T6 Al alaşımının hem ilerleme tarafında hem de geri çekme tarafında farklı plastik deformasyon davranışı gerçekleştirmesinden kaynaklanmaktadir.

Birleştirilen numunelerden başlangıç, orta ve son kısmı olmak üzere üç adet çekme numunesi alınarak çekme testleri gerçekleştirilmiştir. Çekme dayanımı bu üç çekme testinin aritmetik ortalaması alınarak hesaplanmıştır (Şekil 7).

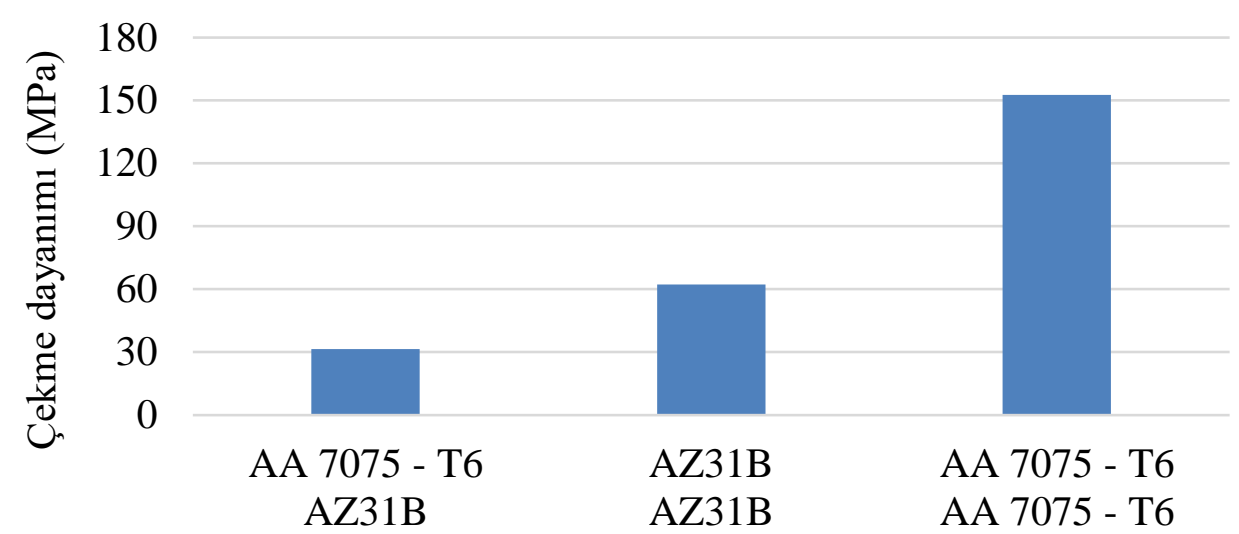

Şekil 7. SKK yöntemi ile Birleştirilmiş Al-Mg, Al-Al, Mg-Mg malzeme çiftlerinin çekem dayanımları

Şekil 7 incelendiğinde AA 7075-T6/AZ31B alaşımlarının birleştirildiği numunede çekme dayanımı 31,48 MPa'dır. Bu değer çekme dayanımı daha düşük ana metal olan AZ31B'nin (240 MPa) \%13,11' dir. Aynı alaşımların birleştirildiği AA7075-T6/AA7075-T6 ve AZ31B/AZ31B numunelerde çekme dayanımları sırasıyla 62,34 MPa ve 152,75 MPa olmuştur. Mg alaşımlarının birleştirildiği numunede çekme dayanımın ana malzeme AZ31B nin çekme dayanımına oranı \% 25,97'dir. Al aşımlarının birleştirildiği numunedeki kaynak dayanımı ise ana malzeme AA 7075T6 (580 MPa) alaşımının \% 26,33’ü olarak gerçekleşmiştir.

Kaynaklı numunelerin çekme dayanımlarının ana malzemelere göre düşük çıkması radyografik muayenede belirlenen tünel oluşumundan kaynaklanmaktadır. Karıştırma bölgesinde oluşan tünel çekme numunesinde kesit daralması yapmasının yanı sıra çentik etkisine neden olduğundan kaynak dayanımını olumsuz yönde etkilemektedir.

Aynı tür malzemelerin birleştirilmesindeki (Al-Al ve Mg-Mg) çekme dayanımları ana malzeme ile kıyaslandığında birbirlerine yakın çıkarken faklı malzemelerin (Al-Mg) birleştirilmesinde çekme dayanımı ana malzemeye kıyasla daha düşük olmuştur. $\mathrm{Bu}$ durum $\mathrm{Al}-\mathrm{Mg}$ alaşımlarının birleştirilmesinde oluşan iri taneli, gevrek ve yüksek sertlikteki Al-Mg intermetalik bileşiklerinden $\left(\mathrm{Al}_{3} \mathrm{Mg}_{2}(\beta)\right.$ ve $\left.\mathrm{Al}_{12} \mathrm{Mg}_{17}(\gamma)\right)$ kaynaklandığı düşünülmektedir [10].

\section{Sonuçlar}

Bu çalışmada, farklı özelliklere sahip AA7075T6 ve AZ31B alaşımları, Al-Al, Mg-Mg ve Al-Mg şeklinde aynı tür ve farklı tür malzemeler olarak SKK yöntemi ile sabit işlem parametreleri ile birleştirilmiştir. SKK işleminde çatlak oluşumunun engellenmesi için kontrollü soğutma işlemi uygulanmıştır. Deneylerden elde edilen bulgular aşağıdaki şekilde özetlenebilir; 
- Al-Al birleştirme hariç Al-Mg ve $\mathrm{Mg}-\mathrm{Mg}$ alaşımlarının birleştirilmesinde kaynak başlangıçlarında sürekli olmayan boşluk hataları görülmüştür. Bu hataların kaynak hattı başlangıcında görülmesi, sürekli olmaması ve devamında ortadan kaybolması düşük 1S1 girdisinin bir sonucu olduğu düşünülmektedir.

- Birleştirmelerde kaynak hattının sonuna yaklaştıkça takıma malzeme yapışmasının sonucu baskı kuvvetinin artırmasıyla çapak oluşumları gözlemlenmiş̧ir.

- Gözle muayene ve penetrant testlerine göre başarılı bir birleştirme elde edildiği görülmüştür. Ancak, radyografik test sonuçlarında her üç birleştirme türünde de kaynak dayanımını düşüren tünel oluşumlarının meydana geldiği görülmüştür.

- Sicak hava uygulamasının kaynak hattında sıcak çatlak oluşumunu engellediği görülmüştür.

- AA 7075-T6/AZ31B alaşımlarının birleştirildiği numunede çekme dayanımı 31,48 MPa, aynı alaşımların birleştirildiği AA7075 - T6 / AA7075 - T6 ve AZ31B / AZ31B numunelerde çekme dayanımları sırasıyla 62,34 MPa ve 152,75 MPa olarak ölçülmüştür.

\section{Teşekkür}

Bu çalışma, Gazi Üniversitesi Bilimsel Araştırma Projeleri Birimi tarafından "BAP 59/2016-01" kodlu proje ile desteklenmiştir. Desteklerinden dolayı Gazi Üniversitesine teşekkür ederiz. Araştırmacılar; test numunelerinin hazırlanmasında Poyraz CNC firmasına ve Şakir Şeker'e, ve tahribatsız muayene testlerinin yapılmasında Tamer Küsen'e vermiş oldukları desteklerden dolayı teşekkür ederler.

\section{Kaynaklar}

[1] Huang G, Kouc S. Partially melted zone in aluminum welds - liquation mechanism and directional solidification. Welding Research Supplement, May 2000; 113-120.

[2] Oğuz B. Demirdışı Metallerin Kaynăğ Metalurji Uygulama, İstanbul: Oerlikon Yayınları; 1990.

[3] Thomas WM, Nicholas, ED. Friction Stir Welding for the Transportation Industries. Materials Design. 1997;18:269-273.

[4] Avedesian M M, Baker H. ASM Specialty Handbook, Magnesium and Magnesium Alloys, USA: ASM International; 1999

[5] Czerwinski F. Welding and Joining of Magnesium Alloys, Magnesium Alloys. In: Czerwinski F, editors. Design, Properties and Applications. Rijeka: Intech; 2011, p. 469-490.

[6] Mofid MA, Abdollah-zadeh A, Malek Ghaini F. The effect of water cooling during dissimilar friction stir welding of Al alloy to Mg alloy. Materials and Design. 2012; 36:161-167.

[7] Zhang Z, Wan ZY. Predictions of tool forces in friction stir welding of AZ91 magnesium alloy. Science and Technology of Welding and Joining. 2012;17(6): 495-501.

[8] Yan J, Xu Z, Li Z, Li L, Yang, S. Microstructure characteristics and performance of dissimilar welds between magnesium alloy and aluminum formed by friction stirring. Scripta Materialia. 2005;53(5): 585-589.

[9] Mishra RS, De PS, Kumar N. Friction Stir Welding and Processing: Science and Engineering. Switzerland: Springer International Publishing; 2014. 
[10] Bilgin M. Alüminyum / Magnezyum (Al / Mg) malzeme çiftinin sürtünme karıştırma kaynağ1 ile kaynak edilebilirliğinin araştırılması. Gazi Üni., Fen Bil. Ens., Doktora Tezi, 2019.

[11] İpekoğlu G, Erim S, Çam G. Effects of temper condition and post weld heat treatment on the microstructure and mechanical properties of friction stir butt-welded AA7075 Al alloy plates. The Int. Journal of Adv. Man. Tech. 2014;70(1-4): 201-213.

[12] Sunil BR, Reddy GPK, Mounika ASN, Sree PN, Pinneswari PR, Ambica I, Babu RA, Amarnadh P. Joining of AZ31 and AZ91 Mg alloys by friction stir welding. Journal of Magnesium and Alloys. 2015;3(4):330-334.

[13] Sarsılmaz F, Özel S, Candan İ. Sürtünme Karıştırma Kaynak Yöntemiyle Birleştirilen Farklı Tipteki Alüminyum Bağlantıların Tahribatlı ve Tahribatsız Muayenesi. Süleyman Demirel Üniversitesi Fen Bilimleri Enstitüsü Dergisi. 2009;13(1): 88-95

[14] Bilgin M, Karabulut Ş, Özdemir A. AA7075-T6 ve AZ31B Alaşımlarının Sürtünme Karıştırma Kaynağı Üzerinde Ön Isıtma ve Kuru Buz Soğutmasının Etkisi. Politeknik Dergisi. 2019; 22(3): 655-663

[15] TS EN ISO 3452-1. Tahribatsız muayene- Penetrant muayenesi- Bölüm 1: Genel kurallar, Ankara: TSE; 2013.

[16] TS EN ISO 3452-2. Tahribatsız muayene - Penetrantla muayene - Bölüm 2: Penetrant maddelerinin deneyi, Ankara: TSE; 2014.

[17] TS EN ISO 23277. Kaynakların tahribatsız muayenesi - Kaynakların penetrant muayenesi Kabul seviyeleri, Ankara: TSE; 2015,

[18] TS EN ISO 3059:2012. Tahribatsız muayene - Penetrantla muayene ve manyetik parçacıkla muayene - İnceleme şartları, Ankara: TSE; 2013.

[19] ASTM E8 / E8M-09. Standard Test Methods for Tension Testing of Metallic Materials, West Conshohocken: ASTM International; 2009.

[20] Ghidini T, Vugrin T, Dalle Donne C. Residual stresses, defects and non-destructive evaluation of FSW joints. Welding International. 2005;19(10):783-790.

[21] Yamamoto N, Liao J, Watanabe S, Nakata K. Effect of intermetallic compound layer on tensile strength of dissimilar friction-stir weld of a high strength $\mathrm{Mg}$ alloy and $\mathrm{Al}$ alloy. Materials Transactions, 2009;50(12):2833-2838.

[22] Zettler BR Augusto A, Rodrigues S, Blanco A. (2006). Dissimilar Al to Mg alloy friction stir welds. Advanced Engineering Materials, 2006;8(5):415-421.

[23] Azizieh M, Alavijeh AS, Abbasi M, Balak Z, Kim HS. Mechanical properties and microstructural evaluation of AA1100 to AZ31 dissimilar friction stir welds. Materials Chemistry and Physics journal, 2016;171:251-260.

[24] Firouzdor V, Kou S. (2009). Al-to-Mg Friction Stir Welding : Effect of Positions of Al and Mg with Respect to the Welding Tool. The Welding Journal, 2009;88(11):213-224.

[25] Mehta KP, Badheka VJ. A review on dissimilar friction stir welding of copper to aluminum: process, properties and variants. Mat. and Man. Processes, 2016;31(3):233 - 254.

[26] Bergmann JP, Schuerer R, Ritter K. Friction Stir Welding of Tailored Blanks of Aluminum and Magnesium Alloys. Key Engineering Materials, 2013;549:492-499.

[27] Cao XJ, Jahazi M. Friction stir welding of dissimilar AA 2024-T3 to AZ31B-H24 alloys. Materials Science Forum, 2010;638-642,3661-3666. 